\title{
Adubação potássica em características agronômicas e pós-colheita de melancia
}

\author{
Taiuan Bruno Almeida Gomes ${ }^{\mathrm{a}}{ }^{\oplus}$, Aline Torquato Tavares ${ }^{\mathrm{a}}{ }^{*}$, João Francisco Matos Neto ${ }^{\mathrm{a}}$, \\ Irais Dolores Pascual Reyes ${ }^{\mathrm{a}}{ }^{\odot}$, Milena Benetti ${ }^{\mathrm{a}} \odot$, João Victor Gonçalves Carline $\mathrm{a}^{\mathrm{a}}{ }^{\odot}$, \\ Fernanda Fonseca Pereira ${ }^{a}{ }^{\oplus}$, Ildon Rodrigues do Nascimento ${ }^{a}{ }^{\circledR}$ \\ ${ }^{\text {a }}$ Universidade Federal do Tocantins, Brasil \\ *Autor correspondente (alinet4t@yahoo.com.br)
}

\section{N F O}

\section{Keywords}

Citrullus lanatus

(Thumb)

nutrition

potassium chloride

Palavras-chaves

Citrullus lanatus

(Thumb)

nutrição

Cloreto de potássio

\begin{abstract}
A B S T R A C T
Potassic fertilization in agronomic and post harvest waters characteristics

The fertilizations with potassium are essentials to the development of watermelon fruit since its formation, ripening, texture and palatability. The objective in this work was to evaluate the effect of potassic fertilization in agronomy characteristics and postharvesting of watermelon. The experimental outline was a randomized block with four replications. Five doses of potassic fertilization were tested, which were: 0; $60 ; 120 ; 180$ e $240 \mathrm{~kg} \mathrm{ha}^{-1} \mathrm{~K}_{2} \mathrm{O}$ in the form of potassium chloride with concentration of $60 \%$ of $\mathrm{K}_{2} \mathrm{O}$ on basic and two fertilizers of cover. The other nutritional requirements of the culture were made according to the nutritional need. The cultivar used was the Manchester ${ }^{\circledR}$, using six plants per plot. The irrigation was realized with drip hoses. For assist of the control of weeds and moisture, was used mulching. Evaluated total average productivity (in ton ha-1), weight of fruits (in $\mathrm{kg}$ ), rind thickness in the peduncle region (in $\mathrm{cm}$ ), of distal region (in $\mathrm{cm}$ ) and total soluble solids ( ${ }^{\circ} \mathrm{Brix}$ ). The rind thickness in the peduncle and distal region weren't altered by potassium doses. As it is a fruit that has the amount of brix or soluble solids as an important factor, the highest $10.3^{\circ}$ BRIX value was observed in the dose of $107.22 \mathrm{~kg}$ of $\mathrm{K} 2 \mathrm{O} \mathrm{ha}{ }^{-1}$, which is the most indicated. The increase in the potassium dose promotes a quadratic response to the characteristics of productivity, average fruit weight and ${ }^{\circ}$ Brix. The thickness of the peel is not affected by the increase in the dose of potassium. The maximum fruit yield estimated at 35 ton ha ${ }^{-1}$ was achieved at a dose of $156.83 \mathrm{~kg}$ of $\mathrm{K} 2 \mathrm{O} \mathrm{ha} \mathrm{h}^{-1}$.
\end{abstract}




\section{INTRODUÇÃO}

A melancia (Citrullus lanatus (Thumb.) Matsum e Nakai), é cultivada em vários países do mundo, com uma produção mundial em torno de 118.413.465 toneladas (FAO, 2017). Segundo Dias e Santos (2019), a produção brasileira correspondeu a 2.314.700 toneladas e área colhida de 105.064 hectares, sendo as maiores regiões produtoras Nordeste, Sul e Norte, já para o estado do Tocantins no mesmo ano a produção foi de 179.180 toneladas em uma área colhida de 6.369 hectares.

O Tocantins possui condições edafoclimáticas favoráveis ao cultivo de frutas tropicais. As condições de clima, solo e água são adequadas, viabilizando a produção, que associados aos fatores de boa disponibilidade de área e localização próxima aos grandes centros, das capitais do centro-oeste, norte e nordeste, o torna com grande potencial para a exploração da cultura (Tavares et al., 2014). Os municípios de Lagoa da Confusão, Cristalândia e Formoso do Araguaia são destaques de produção da fruta no estado, com uma produção estimada em 87.500, 28.200 e 16.000 toneladas, respectivamente (IBGE, 2018).

A produtividade, peso médio e a qualidade dos frutos de melancia estão associadas principalmente a fatores genéticos, climáticos e fitotécnicos, sendo a nutrição da planta de fundamental importância para se conseguir resultados satisfatórios (Gonsalves et al., 2009).

O potássio desempenha várias funções na bioquímica e fisiologia da planta e melhora a qualidade dos frutos, é o catíon com maior concentração nos tecidos vegetais, sendo absorvido em grandes quantidades da solução do solo pelas raízes das plantas na forma de $\mathrm{K}^{+}$, por não formar composto orgânico ele é bastante móvel na planta, além de ser facilmente trocável nos tecidos ou nas células com alta mobilidade celular (Gurgel et al., 2010).

Raij (1990) confirma a importância do potássio, destacando a contribuição para melhora dos atributos como a cor, acidez, resistência ao transporte, armazenamento de fotoassimilados, além da disponibilidade de outros nutrientes.

O cloreto, o nitrato e o sulfato de potássio são os principais fertilizantes utilizados, a escolha de uma dessas fontes deve estar relacionada a alguns fatores como a necessidade da cultura, o método de aplicação, preço e a disponibilidade para aquisição. O cloreto de potássio na cultura da melancia, é a fonte mais utilizada devido ao seu menor valor no mercado. (Cecílio Filho e Granjeiro, 2004a).
A deficiência desse macronutriente não apresenta nítidas evidências em folhas, porém, em casos mais severos, podem ocorrer o secamento de margens do limbo em folhas novas, tamanho de frutos reduzidos, casca fina e lisa são frequentes, como a maturação precoce e também a queda prematura do fruto, além de murchas, cloroses e necroses marginais nas folhas mais velhas (Taiz e Zieger, 2013).

O potássio tem sua importância em diversas atividades metabólicas na planta que estão ligadas principalmente à características qualitativas do fruto, desta forma ter o conhecimento de uma adubação ideal para seu incremento é de suma necessidade, com este trabalho, objetivou-se avaliar o efeito da adubação potássica em características agronômicas e de frutos de melancia.

\section{MATERIAL E MÉTODOS}

O experimento foi instalado no Estado do Tocantins, na latitude sul $11^{\circ} 43^{\prime} 45^{\prime \prime}$ e longitude oeste $49^{\circ} 04^{\prime} 07^{\prime \prime}$ com altitude média de $280 \mathrm{~m}$. A classificação climática segundo Köppen (1948) caracteriza a região como tipo B1wA'a' (úmido com moderada deficiência hídrica). Durante a realização do ensaio a precipitação pluvial totalizou $114 \mathrm{~mm}$ e a temperatura média $26,7^{\circ} \mathrm{C}$ (Figura 1).

$\mathrm{O}$ solo da região é classificado como Latossolo Vermelho Amarelo Distrófico. Com relação as características de solo foi realizado uma análise do solo $(0-20 \mathrm{~cm})$ anteriormente a instalação do experimento (Tabela 1).

De acordo com a análise de solo foi recomendada a calagem com cerca de 1,26 toneladas por hectare de calcário pelo método de elevação dos níveis de cálcio e magnésio para teores considerados bons (Alvarez et al., 1999). A aplicação do calcário foi realizada cerca de 60 dias antes do plantio da cultura, utilizando-se calcário dolomítico. Foram realizadas operações de preparo do solo, com uma aração e uma gradagem. O levantamento dos canteiros realizou-se com rotoencanteirador de $70 \mathrm{~cm}$ de largura. Para a irrigação foram instaladas mangueiras gotejadoras com turno de rega de uma hora em duas vezes ao dia de acordo com a capacidade de retenção de água do solo, observado visualmente pelo teor de umidade, de modo que não formasse lâmina de água na superfíce. Para o controle das plantas daninhas e controle de umidade foi utilizado o mulching. A condução do cultivar foi realizado de forma convencional. 


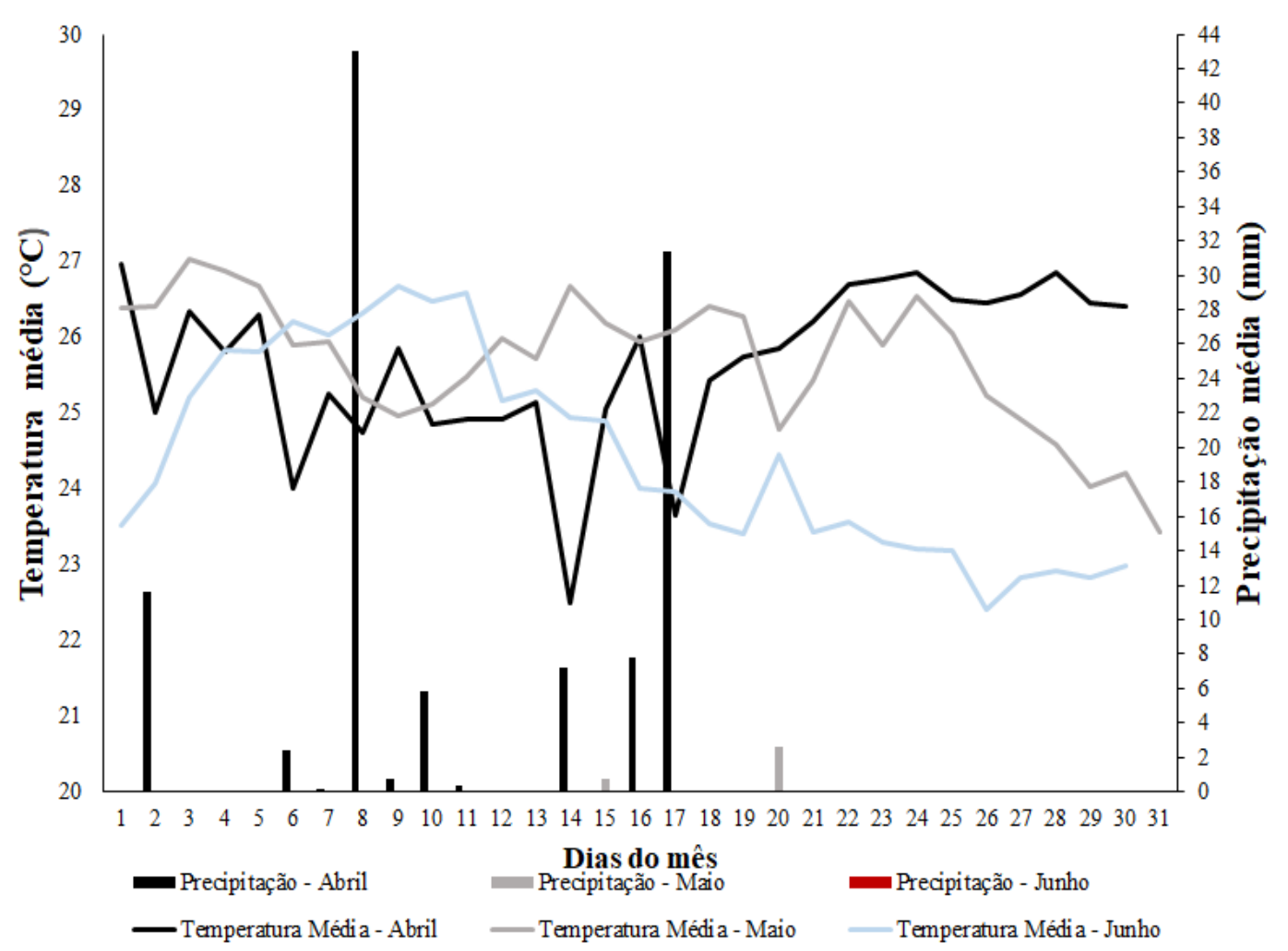

Figura 1 - Temperaturas e precipitações médias nos meses do experimento, na estação meteorológica em Gurupi-TO, 2018.

O delineamento experimental utilizado foi o de blocos casualizados com quatro repetições. Cada parcela foi constituída por seis plantas espaçadas em $2,65 \mathrm{~m} \times 0,65 \mathrm{~m}$, sendo avaliadas as quatro plantas centrais. Foi utilizado frutos do tipo Crimson Sweet, cultivar híbrido Manchester®, da Syngenta, escolhido principalmente por ser o mais plantado no estado do Tocantins, além de ter uma maior resistência e duração pós colheita.

A semeadura foi realizada em bandejas de poliestireno expandido de 128 células com substrato comercial Plantmax ${ }^{\circledR}, \quad$ irrigadas diariamente, de maneira a manter o substrato sempre úmido até serem transplantadas por volta de 10 dias após semeadura.

De acordo com a análise de solo a recomendação de potássio foi $120 \mathrm{Kg}$ de $\mathrm{K}_{2} \mathrm{O}$ ha $^{-1}$ então os tratamentos consistiram de aplicação de doses crescentes desse nutrientevia solo, as quais foram: 0; 60; 120; 180 e $240 \mathrm{Kg}$ de $\mathrm{K}_{2} \mathrm{O} \mathrm{ha}^{-1}$, utilizando como fonte de potássio o adubo cloreto de potássio ( $\mathrm{KCl}$ com garantia mínima de $60 \%$ de $\mathrm{K}_{2} \mathrm{O}$ ). Para a adubação de base foi utilizado $310 \mathrm{Kg} \mathrm{ha}^{-1}$ de MAP (Mono-Amônio-Fosfato) como fonte de Nitrogênio (12\%) e Fósforo (52\%).

Tabela 1 - Resultados da análise de solo de 0 a $20 \mathrm{~cm}$ de profundidade. Gurupi-TO, 2018.

\begin{tabular}{|c|c|c|c|c|}
\hline $\begin{array}{c}\mathbf{p H} \\
\left(\mathrm{CaCl}_{2}\right) \\
\end{array}$ & $\begin{array}{c}\text { P meh } \\
\left(\mathrm{mg} \cdot \mathrm{dm}^{-3}\right)\end{array}$ & $\begin{array}{c}\mathbf{K} \\
\left(\mathrm{cmolc}^{\left.-\mathrm{dm}^{-3}\right)}\right.\end{array}$ & $\begin{array}{c}\mathbf{C a} \\
\left(\mathrm{cmolc}^{\left.-\mathrm{dm}^{-3}\right)}\right)\end{array}$ & $\begin{array}{c}\mathbf{M g} \\
\left(\mathrm{cmolc} . \mathrm{dm}^{3}\right) \\
\end{array}$ \\
\hline 5,4 & 7,7 & 0,12 & 1,5 & 0,6 \\
\hline $\begin{array}{c}\text { Al } \\
\left(\mathrm{cmolc}^{-\mathrm{dm}^{-3}}\right)\end{array}$ & $\begin{array}{c}\mathbf{H}+\mathbf{A l} \\
\left(\mathrm{cmolc} \cdot \mathrm{dm}^{-3}\right)\end{array}$ & $\begin{array}{c}\text { M.O } \\
\left(\text { dag. } \mathrm{Kg}^{-1}\right)\end{array}$ & $\begin{array}{c}\text { C.O } \\
\left(\text { dag. } \mathrm{Kg}^{-1}\right)\end{array}$ & $\begin{array}{l}\text { Argila } \\
\left(\mathrm{g} . \mathrm{Kg}^{-1}\right)\end{array}$ \\
\hline 0,00 & 3,10 & 1,4 & 0,8 & 325 \\
\hline $\begin{array}{c}\text { SB } \\
\left(\mathrm{cmolc}^{\left.-\mathrm{dm}^{-3}\right)}\right.\end{array}$ & $\begin{array}{c}\text { CTCt } \\
\left(\mathrm{cmolc} . \mathrm{dm}^{-3}\right)\end{array}$ & V\% & & \\
\hline 2,22 & 5,32 & 42 & & \\
\hline
\end{tabular}


De acordo com a recomendação de Mendes et al., (2010) e Filgueira et al., (1999) foi utilizado 10 toneladas por hectare de esterco bovino para adubação orgânica. Para adubações de cobertura após 30 e 60 dias de transplantio foram usados 182 $\mathrm{Kg} \mathrm{ha}^{-1}$ de Ureia ( $46 \%$ de $\mathrm{N}$ ) e $\mathrm{KCl}$ como fonte de potássio, sendo aplicado por vez $30 \%$ do $\mathrm{N}$ e $\mathrm{K}_{2} \mathrm{O}$.

Para o controle de pragas e doenças foram realizadas aplicações semanais de mancozebe, tiofanato-metílico, oxicloreto de cobre, imidacloprido, clorantraniliprole e piriproxifen, rotacionando o ingrediente ativo e seguindo as recomendações técnicas de manejo da cultura para prevenção e controle fitossanitário. Foram realizadas também capinas manuais para eliminação de daninhas entre canteiros, raleio de frutos para retirada de frutos mal formados $\mathrm{e}$ condução das plantas para facilitar o manejo da cultura.

A colheita foi realizada aos 70 dias após o transplantio quando os frutos estavam maduros. As características avaliadas foram:

- Produtividade média de frutos (PR em ton $\left.\mathrm{ha}^{-1}\right)$ : obtida através do peso médio de frutos multiplicado pelo número de frutos colhidos em cada parcela e o resultado foi convertido para ton $\mathrm{ha}^{-1}$;

- Peso médio dos frutos (PF, em kg): obtido pela relação do peso dos frutos colhidos da parcela útil pelo número de colhidos;

- Espessura média da casca na região do pedúnculo - haste de ligação do fruto com a planta $(\mathrm{ECP}, \mathrm{em} \mathrm{cm})$ e na região distal - região localizada na parte mediana do fruto (ECD, em $\mathrm{cm}$ ), obtida através do uso do paquímetro digital.

- Teor de açúcares totais ( ${ }^{\circ}$ Brix), quantificado através do uso de refratômetro portátil.
Os dados médios de cada tratamento para cada característica avaliada foram submetidos à análise de variância (ANAVA). Em seguida foi feito ajuste de modelo que melhor descrevesse a variação dos dados observados. As análises estatísticas foram feitas com o programa SISVAR (Ferreira, 2011), e as curvas de regressão e plotagem dos gráficos pelo programa Sigmaplot 10.0 (Systat Software Inc.).

\section{RESULTADOS E DISCUSSÃO}

Os resultados obtidos mostram que a produtividade $\left(\mathrm{t} \mathrm{ha}^{-1}\right)$, peso médio de frutos $(\mathrm{Kg}) \mathrm{e}$ teor de açúcares totais $\left({ }^{\circ}\right.$ Brix) tiveram efeito significativo da dose de potássio aplicada. Já espessura média da casca na região do pedúnculo (cm) e espessura média da casca na região distal (cm) os resultados foram não significativos.

Foram observados dois grupos de coeficiente de variação onde o primeiro ficou entre 4 e $6 \%$ e o segundo entre 22 e $31 \%$. A produtividade, peso médio dos frutos e teor de sólidos solúveis foram considerados baixos mostrando que essas características são mais influenciadas pelas doses de potássio do que por fatores aleatórios. Já para espessuras de casca foi considerado alto, pois são características onde sua variação é independente das doses de potássio, sendo difícil prever seu comportamento diante da adubação.

Para produtividade de frutos em função das doses de potássio, seu ponto máximo atingido por meio da análise de regressão quadrática foi na dose de $156,83 \mathrm{Kg}$ de $\mathrm{K}_{2} \mathrm{O}$ ha $^{-1}$, onde se obteve a produtividade próxima de 35 ton $\mathrm{ha}^{-1}$ sendo considerada acima da média nacional e estadual que são de 22 ton ha ${ }^{-1}$ e 28 ton ha ${ }^{-1}$, respectivamente (IBGE, 2018) (Figura 2).

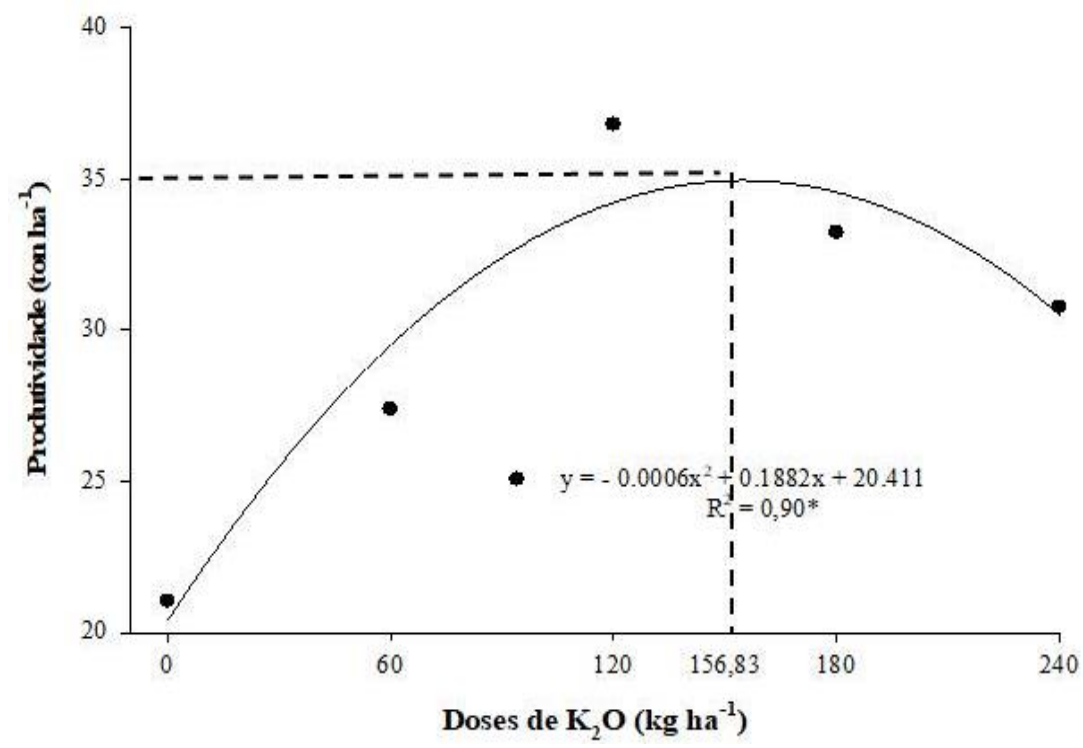

Figura 2 - Produtividade de frutos de melancia, híbrido Manchester, em função das doses de $\mathrm{K}_{2} \mathrm{O}$. 
Cecílio Filho e Grangeiro (2004a), avaliando a produtividade de melancia com fontes e doses de potássio em duas épocas (safra e safrinha), constataram que a produtividade em função das doses de potássio também apresentou comportamento quadrático com as doses de 132; 193 e $205 \mathrm{Kg}_{\text {de }} \mathrm{K}_{2} \mathrm{O}$ ha $^{-1}$, respectivamente, para as fontes de $\mathrm{K}_{2} \mathrm{SO}_{4}, \mathrm{KNO}_{3}$ e $\mathrm{KCl}$, sendo as produtividades de 32,$4 ; 34,4$ e 32,4 ton $\mathrm{ha}^{-1}$ no período da safra. Segundo o autor foi necessária a aplicação de 73 e $61 \mathrm{Kg}_{\text {de }} \mathrm{K}_{2} \mathrm{O}$ ha $^{-1}$ a mais de $\mathrm{KCl}$ e $\mathrm{KNO}_{3}$ para atingir a produtividade máxima em relação ao $\mathrm{K}_{2} \mathrm{SO}_{4}$, sendo um total de acréscimos de 55 e $46 \%$. Como a principal explicação para tal eficiência do $\mathrm{K}_{2} \mathrm{SO}_{4}$, que o ânion $\mathrm{SO}_{4}{ }^{2-}$ em relação ao $\mathrm{Cl}^{-}$e $\mathrm{NO}^{3-}$ tem maior possibilidade de adsorção e menor lixiviação no solo, tendo as perdas de $\mathrm{K}^{+}$ minimizadas e consequentemente estando disponível e absorvido em maior quantidade pela planta.

Nascimento et al., (2017), também trabalhando com melancia, usando esterco bovino e potássio encontraram com uma menor dose a produtividade de 23 ton ha ${ }^{-1}, 30 \mathrm{Kg}$ de $\mathrm{K}_{2} \mathrm{O}$ ha- 1 e $1,10 \mathrm{Kg}$ de esterco bovino por cova, sendo destacado que o maior fornecimento da matéria orgânica influenciou no aumento da eficiência da adubação com esse nutriente. A M.O eleva o pH e aumenta a CTC do solo desta forma contribui para uma maior disponibilidade e adsorção de nutrientes catiônicos como o K ${ }^{+}$pelas plantas (Menezes e Silva, 2008). Também melhora a estrutura do solo e aumenta a retenção de água, diminuindo assim a percolação e lixiviação (Roberts e Ryan, 2015). Diante disso a adubação orgânica com estercos associada a uma adubação potássica é necessária para aumentar a eficiência na absorção desse nutriente além de reduzir suas perdas no solo (Nicolae et al., 2014). A adubação orgânica é inviavél em lavouras comerciais, tanto pelo preço quanto pela disponibilidade em grande escala, desta forma utilizou-se em condições de experimento por se tratar de pequena quantidade e também para melhoria das características fisícas e químicas do solo. Desta forma uma possível explicação para as melhores doses encontradas no trabalho foi devido a adubação orgânica realizada na área.

Para peso médio de frutos, a melhor dose segundo a análise de regressão quadrática foi de $147 \mathrm{Kg}$ de $\mathrm{K}_{2} \mathrm{O}$ ha $^{-1}$, onde se observou um peso médio de frutos estimados em 10,7 Kg (Figura 3).

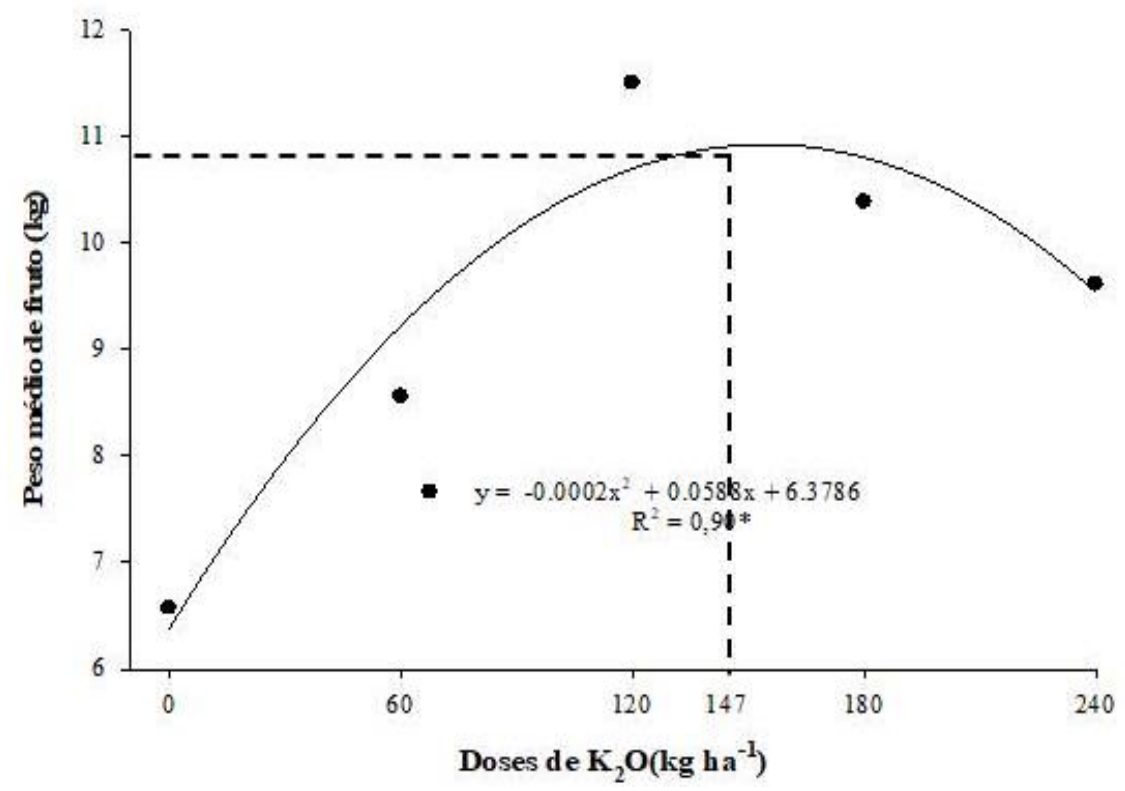

Figura 3 - Peso médio de frutos de melancia, híbrido Manchester, em função das doses de $\mathrm{K}_{2} \mathrm{O}$.

Souza et al., (2016), também avaliaram o peso médio de frutos de melancia, em função de doses de potássio no estado do Tocantins, encontrando $6,65 \mathrm{Kg}$ para a dose de $53,31 \mathrm{Kg}$ de $\mathrm{K}_{2} \mathrm{O}$ ha $^{-1}$. Já Faria et al., (2003), encontraram um peso médio de $7,97 \mathrm{Kg}$ com uma dose de $65,8 \mathrm{Kg}$ de $\mathrm{K}_{2} \mathrm{O}$ ha $^{-1}$ realizando seu trabalho no submédio São Francisco com aplicação via fertirrigação. A adubação potássica é essencial para o aumento do fruto na cultura da melancia, participando de sua formação, amadurecimento e textura (Filgueira, 2003) sendo exigido assim em maior quantidade após a frutificação.

$\mathrm{O}$ aumento do peso em plantas supridas com potássio dá-se ao fato que o acúmulo desse macronutriente induz a uma maior quantidade de água nos tecidos. Ou ainda que exerce importância no enchimento de frutos devido as funções de transporte e armazenamento de fotoassimilados da folha para o fruto, além da expansão das células 
resultando em maior peso e maior tamanho (Rodrigues et al., 2016).

O potássio também atua na ativação de enzimas essenciais a ocorrência de processos metabólicos como síntese proteica, a fotossíntese e a respiração, alterando a forma física da enzima, e deixando expostos os locais quimicamente ativos, adequados para a reação (Armstrong, 1998).

No transporte dos produtos resultantes da fotossíntese através do floema requer energia na forma de ATP. O potássio possui envolvimento na produção de adenosina trifosfato (ATP), segundo Armstrong (1998) sua função seja possivelmente mais importante, quando o potássio atua na regulação da taxa fotossintética do que na atividade estomática, explicado pelo fato de que o equilíbrio entre as cargas elétricas onde se é produzido ATP é mantido com íons de $\mathrm{K}^{+}$, deste modo, plantas deficientes em K, são reduzidas a taxa de produção de ATP e consequentemente fotossíntese, reduzindo todos os processos metabólicos que dependem de ATP.

Na planta, nutrientes como o nitrogênio e o potássio possuem alta mobilidade e a sua redistribuição ocorre das áreas de síntese (folhas) as áreas de crescimento (frutos) e armazenamento (Malavolta, 1980).

A produtividade e peso médio de frutos estão intimamente relacionados, mostrando que o macronutriente potássio é essencial para o incremento dos mesmos. Nota-se ainda que participa de diversos processos metabólicos na planta e portanto o não suprimento adequado acarreta a um decréscimo dessas características.

Os teores de açúcares totais expresso em ${ }^{\circ}$ Brix segundo a análise de regressão quadrática responderam ao aumento da adubação potássica com o valor próximo de $10,3^{\circ}$ Brix na dose de $107,22 \mathrm{Kg}$ de $\mathrm{K}_{2} \mathrm{O}$ ha $^{-1}$ tendo a partir de então uma redução, atingindo $8,7^{\circ}$ Brix na maior dose aplicada (Figura 4).

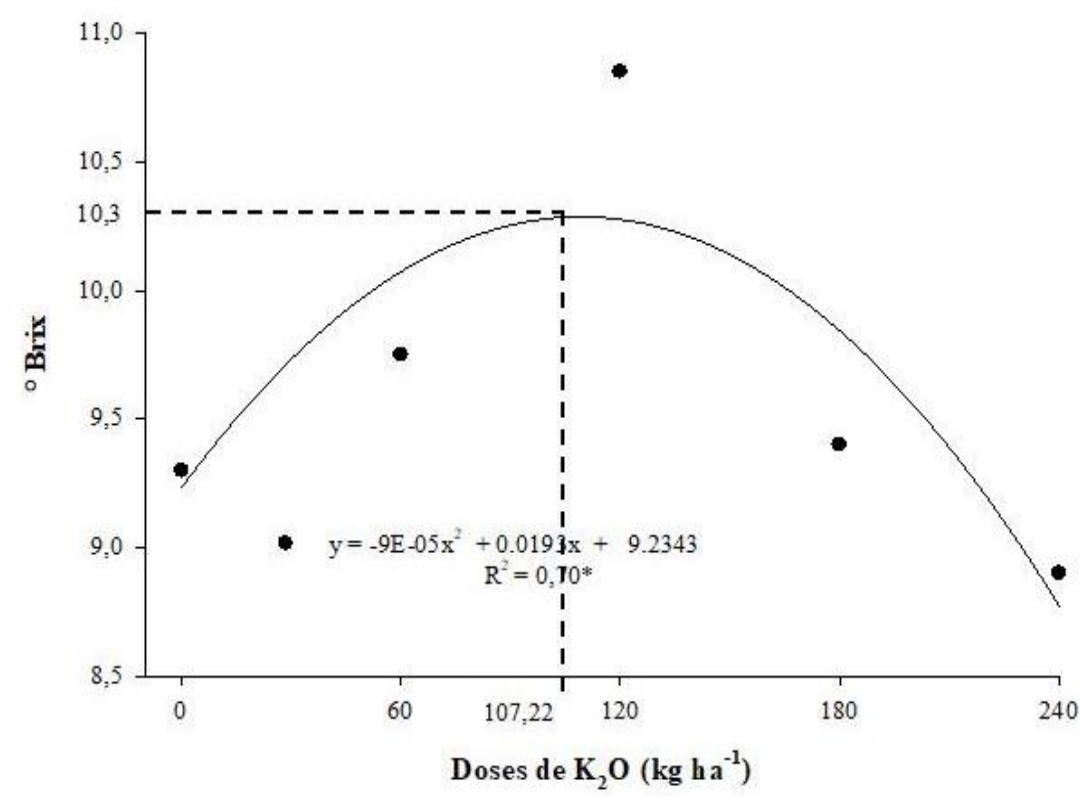

Figura 4 - Teor de açúcares totais expresso em ${ }^{\circ}$ Brix em fruto de melancia, híbrido Manchester, em função das doses de $\mathrm{K}_{2} \mathrm{O}$.

Os teores de açúcares totais em frutos de melancia, fornecem um indicador da quantidade de açúcares presente nas frutas, tendo grande influência na aceitação do produto pelo consumidor final, não só no Brasil mais também em outros países este índice é bastante considerado na determinação da qualidade de frutos (Bleinroth, 1994).

O valor de $10,3^{\circ}$ Brix encontra-se dentro dos padrões, pois o mínimo exigido para a colheita de melancia de acordo com a União Européia é de $9^{\circ}$ Brix, sendo mais aceitos pelo mercado valores acima de $10^{\circ}$ Brix (Dias e Lima, 2010).

Silva et al., (2015), estudando os teores de açúcares totais em melancia com adubação nitrogenada e potássica encontraram $8,5^{\circ}$ Brix para a dose de $38,57 \mathrm{Kg} \mathrm{ha}^{-1}$ de $\mathrm{N}$ e K. Cecílio Filho e Grangeiro (2004b), também verificaram o aumento do teor açúcares totais em melancia com adubação potássica, sendo utilizado o híbrido sem sementes Shadow, encontrando o valor máximo de $12,3^{\circ}$ Brix com aplicação de $140 \mathrm{Kg}$ de $\mathrm{K}_{2} \mathrm{O}$ ha $^{-1}$. Segundo os autores valores mais elevados de açúcares totais em frutos, em função do aumento da 
dose de potássio na adubação, tem relação com o importante papel que este nutriente desenvolve na ativação de diversas enzimas e também na translocação de fotossintatos.

O potássio promove o transporte de fotossintatos para os órgãos de armazenamento das plantas como os frutos, grãos, tubercúlos, e participa na formação e translocação de açúcares, melhorando seu tamanho, cor e qualidade, além do aumento da conversão dos mesmos em amido, proteína, vitaminas, óleos e outros. Já Raij et al. (1991) afirmam que o $\mathrm{K}^{+}$é um ativador de funções de manutenção da turgidez das células que atua na movimentação de fotoassimilados nos tecidos vegetais, podendo ainda aumentar o valor nutritivo das plantas.

Tanto para produtividade, peso médio de frutos e teor de sólidos solúveis houve comportamento quadrático crescente em resposta as doses utilizadas, caindo a partir da dose ideal encontrada, mostrando que com doses elevadas, ou seja com o excesso do potássio há influência direta na redução das caracteristicas avaliadas. Dias et al. (2016), ressalta que o excesso de sais atuam desbalanceando e causando danos ao citoplasma visto que as plantas os absorvem juntamente com a água, promovendo assim uma maior perda por transpiração, ou ainda que o excesso pode causar um efeito osmótico inverso onde a célula perde água devido a solução exterior à planta estar mais concentrada. Também pode ocorrer o desequilíbrio nutricional de $\mathrm{Ca}$ e $\mathrm{Mg}$ causado por excesso de $\mathrm{Cl}^{-}$ através da competição iônica, além da diminuição da concentração de $\mathrm{NH}_{4}{ }^{+}$nos tecidos, devido ao efeito competitivo entre os elementos (Chen e Mackenzie, 1992; Marschner, 2011).

Asch et al. (2000) enfatiza que a grande concentração de íons no solo especialmente $\mathrm{Na}^{+} \mathrm{e}$ $\mathrm{Cl}^{-}$, podem promover a toxicidade no vegetal além do desequilíbrio na homeostase do potencial de água, afetando a produção de fitomassa e assim o crescimento do vegetal. Através da intereção iônica o excesso de um nutriente também pode causar a diminuição na absorção de outro (Porto et al. 2015). Para a espessura de casca na região do pedúnculo (haste de ligação do fruto com a planta) e na região distal (região localizada na parte mediana do fruto) não houve diferença significativa entre as doses de potássio utilizadas.

Rodrigues et al. (2016), também verificaram que diferentes doses de potássio não promoveram efeito significativo na espessura de casca da melancia, o que difere de outros trabalhos como o de Cecílio Filho e Grangeiro (2004b), que utilizando fontes e doses de potássio, observou que a espessura de casca (EC) de frutos de melancia sem sementes foi significativamente influenciada pelas fontes $\mathrm{KCl}$ e
$\mathrm{KNO}_{3}$. Com $\mathrm{KCl}$, a EC foi de $1,24 \mathrm{~cm}$ na dose de $300 \mathrm{~kg} \mathrm{~K}_{2} \mathrm{O} \mathrm{ha}^{-1}$ e com $\mathrm{KNO}_{3}$, a EC foi de $1,27 \mathrm{~cm}$ na dose de $202 \mathrm{~kg} \mathrm{~K}_{2} \mathrm{O} \mathrm{ha}^{-1}$.

\section{CONCLUSÕES}

O aumento da dose de potásio promove resposta quadrática para as características produtividade, peso médio de frutos e ${ }^{\circ}$ Brix. Já a espessura da casca não é afetada pelo aumento da dose de potássio.

A produtividade máxima de frutos estimada em 35 ton ha ${ }^{-1}$ foi alcançada na dose de $156,83 \mathrm{Kg}$ de $\mathrm{K}_{2} \mathrm{O}$ ha $^{-1}$.

A dose de $147 \mathrm{Kg}$ de $\mathrm{K}_{2} \mathrm{O}^{-1}$ promove o maior peso médio de frutos.

O valor 10,3 máximo de ${ }^{\circ}$ Brix é observado na dose de $107,22 \mathrm{Kg}_{\text {de }} \mathrm{K}_{2} \mathrm{O}$ ha $^{-1}$.

\section{REFERÊNCIAS BIBLIOGRÁFICAS}

Alvarez VVH, Novais RF, Barros NF, Cantarutti RB, Lopes AS. Interpretação dos Resultados Das Análises de Solos. In: Ribeiro AC, Guimarães PTG, Alvarez VVH. Recomendações para o uso de corretivos e fertilizantes em Minas Gerais: $5^{\text {a }}$ aproximação. Viçosa, MG: Comissão de Fertilidade do Solo do Estado de Minas Gerais, 27p. 1999.

Armstrong DL. Potassium for agriculture. Better crops with plant food, v.82, 40p. 1998.

Asch F, Dingkuhn M, Dorffing K. Salinity increases CO2 assimilation but reduces growth in field grown, irrigated rice. Plant and Soil. v.218, p.1, 2000.

https://doi.org/10.1023/A:1014953504021

Bleinroth EW. Determinação do ponto de colheita. In: Netto, A.G. (ed.). Melão para exportação: Procedimentos de colheita e pós-colheita. MAARA/FRUPEX: Brasília 37p. 1994.

Cecílio Filho AB, Grangeiro LC. Produtividade da cultura da melancia em função de fontes e doses de potássio. Ciência e Agrotecnologia, v.28, n.3, p.561-569, 2004a. http://dx.doi.org/10.1590/S1413-70542004000300011

Cecílio Filho AB, Grangeiro LC. Qualidade de frutos de melancia sem sementes em função de fontes e doses de potássio. Ciência e Agrotecnologia, v.28, n.3, p.570-572, 2004 b. http://dx.doi.org/10.1590/S1413-70542004000300012

Chen JS, Mackenzie AF. Fixed ammonium and potassium as affected by added nitrogen and potassium in three Quebec soils. Communication in Soil Science and Plant Analysis, v.23, n.11-12, p.1145-1159, 1992.

https://doi.org/10.1080/00103629209368657

Dias NS, Blanco FF, Souza ER, Ferreira JFS, Sousa Neto ON, Queiroz ISR. (2016). Efeitos dos sais na planta e tolerância das culturas à salinidade. In H. R. Gheyi, N. S. Dias, C. F. Lacerda, e E. Gomes Filho (Eds.), Manejo da salinidade na agricultura: Estudo básico e aplicados. INCTSal.

Dias RCS, Lima MAC. 2010. Colheita e Pós-colheita. Petrolina: Embrapa Semiárido. Disponível em: 
$<$ https://sistemasdeproducao.cnptia.embrapa.br/fonteshtml/melancia/sistemaproduca omelancia/colheita.htm>. Acesso em: 15 de Novembro de 2018.

Faria CMB, Costa ND, Pinto JM. Doses de potássio na melancia no submédio São Francisco. Horticultura Brasileira, v.21, n.2, 2003.

Ferreira DF. Sisvar: a computer statistical analysis system. Ciência e Agrotecnologia, v.35, p.1039-1042, 2011. http://dx.doi.org/10.1590/S1413-70542011000600001

Filgueira FAR. Novo Manual de Olericultura: Agrotecnologia moderna na produção e comercialização de hortaliças. Viçosa: UFV, 412p. 2003.

Filgueira FAR, Carrijo IV, Avelar Filho J.A. Melancia. In: Ribeiro AC, Guimarães PT. G, Alvarez VVH. Recomendações para o uso de corretivos e fertilizantes em Minas Gerais: $5^{\text {a }}$ aproximação. Viçosa, MG: Comissão de Fertilidade do Solo do Estado de Minas Gerais, 192p. 1999.

Food and agriculture organization of the United Nations. Faostat, Crops, 2017. Disponível em: < http://www.fao.org/faostat/en/\#data/qc $>$. Acesso em: 27 de Maio de 2019.

Gonsalves MVI, Feltrim AL, Pavani LC, Cecílio Filho AB. Potencial hídrico foliar em híbridos de melancia com e sem semente em função da adubação nitrogenada e potássica e da densidade de plantio. Horticultura Brasileira, v.27, n.2, 2009.

Gurgel MT, Uyeda CA, Gheyi HR, Oliveira FHT, Fernandes PD, Silva FV da. Crescimento de meloeiro sob estresse salino e doses de potássio. Revista Brasileira de Engenharia Agrícola e Ambiental, v.14, n.1, p.3-10, 2010. http://dx.doi.org/10.1590/S1415-43662010000100001

Instituto Brasileiro de Geografia e Estatistica - IBGE. Produção Agrícola Municipal - PAM - Lavoura Temporária. 2018. Disponível em: <https://sidra.ibge.gov.br/tabela/1612\#resultado> Acesso em: 01 de Novembro de 2019.

Köppen W. Climatologia: con un estudio de los climas de la tierra. Fondo de Cultura Econômica. México. 479p. 1948.

Malavolta E. Elementos de nutrição mineral de plantas. 23. ed. São Paulo: Agronômica Ceres. 253p. 1980.

Marschner H. Mineral nutrition of higher plants. 3a ed. New York, Academic Press, 672 p. 2011.

Mendes MAS, Faria CMB , Silva D. S. 2010. Adubação. Petrolina: Embrapa Semiárido. Dísponivel em: <https://sistemasdeproducao.cnptia.embrapa.br/FontesHTML/Melan$\mathrm{cia} /$ SistemaProducaoMelancia/adubacao.htm>. Acesso em: 25 de junho de 2020 .

Menezes RSC, Silva TO. Mudanças na fertilidade de um Neossolo Regolítico após seis anos de adubação orgânica. Revista Brasileira de Engenharia Agrícola e Ambiental, v.12, n.3, p.251-257, 2008.

Nicolae I, Camen D, Lascu N, Marieta P. Research regarding influence of organic fertilization on the physiological processes intensity in watermelon plants. Journal of Horticulture, Forestry and Biotechnology, v.18, n.2, p.78-83, 2014.

Nascimento JAM, Souto JS, Cavalcante LF, Medeiros SAS, Pereira WE. Produção de melancia em solo adubado com esterco bovino e potássio. Agrária, v.12, n.2, p.122-127, 2017. https://doi.org/10.5039/agraria.v12i2a5427

Porto DS, Silva ES da, Carmo ILG da S, Monteiro Neto JLL, Trassato LB, Medeiros RD de. Rendimento da melancia sob doses de fósforo e de potássio no Cerrado de Roraima. In: Congresso Brasileiro de Ciência do Solo, 35. 2015. O solo e suas múltiplas funções: anais. Natal: Sociedade Brasileira de Ciência do Solo, 2015.

Raij BV. Potássio: necessidade e uso na agricultura moderna. Piracicaba: Potafos. 45p. 1990.

Raij BV. Fertilidade do solo e adubação. Ed. Ceres/Potafos, Piracicab: São Paulo. 343p. 1991.

Roberts TL, Ryan J. Solo e segurança alimentar. Informações Agronômicas, 3-5p, 2015.

Rodrigues JCA, Reis LL Dos, Silva CA da. Avaliação da produção e qualidade de frutos de melancia sob diferentes doses de potássio em cobertura. Revista Agrogeoambiental, v.8, n.4, p.11-22, 2016. http://dx.doi.org/10.18406/2316-1817v8n42016857

Silva VFA, Melo NC, Galvão JR, Silva DR, Pereira WVS, Rodrigues FHS. Produção de melancia e teores de sólidos solúveis totais em resposta a adubação nitrogenada e potássica. Revista Brasileira de Agricultura Irrigada, v.9, n.3, p.136-144, 2015. https://doi.org/10.7127/RBAI.V9N300299

Souza JP, Abreu DG, Silva RAMP, Dourado DP, Abreu IMO, Miranda FFR. Influência de doses de potássio sob características agronômicas na cultura da melancia. Revista Integralização Universitária, v.11, n.14, 2016.

Taiz L, Zeiger E. Fisiologia vegetal. 5.ed. Porto Alegre: Artemed, 954p. 2013.

Tavares AT, Cavalcante RR, Barros KKM, Marques KR, Pereira KCG, Nascimento IR. Efeito de doses de 2,4-D sobre características pós-colheita de frutos de melancia. Horticultura Brasileira, v.31, n.2, (Suplemento - CD Rom), 2014. 